\title{
Syndromes associated with mitochondrial DNA depletion
}

\author{
Célia Nogueira ${ }^{1 \dagger}$, Ligia S Almeida ${ }^{1 \dagger}$, Claudia Nesti ${ }^{2}$, Ilaria Pezzini ${ }^{2}$, Arnaldo Videira ${ }^{3}$, Laura Vilarinho ${ }^{1,5^{*}}$ \\ and Filippo M Santorelli $i^{2,4^{*}}$
}

\begin{abstract}
Mitochondrial dysfunction accounts for a large group of inherited metabolic disorders most of which are due to a dysfunctional mitochondrial respiratory chain (MRC) and, consequently, deficient energy production. MRC function depends on the coordinated expression of both nuclear (nDNA) and mitochondrial (mtDNA) genomes. Thus, mitochondrial diseases can be caused by genetic defects in either the mitochondrial or the nuclear genome, or in the cross-talk between the two. This impaired cross-talk gives rise to so-called nuclear-mitochondrial intergenomic communication disorders, which result in loss or instability of the mitochondrial genome and, in turn, impaired maintenance of qualitative and quantitative mtDNA integrity. In children, most MRC disorders are associated with nuclear gene defects rather than alterations in the mtDNA itself.

The mitochondrial DNA depletion syndromes (MDSs) are a clinically heterogeneous group of disorders with an autosomal recessive pattern of transmission that have onset in infancy or early childhood and are characterized by a reduced number of copies of mtDNA in affected tissues and organs. The MDSs can be divided into least four clinical presentations: hepatocerebral, myopathic, encephalomyopathic and neurogastrointestinal. The focus of this review is to offer an overview of these syndromes, listing the clinical phenotypes, together with their relative frequency, mutational spectrum, and possible insights for improving diagnostic strategies.
\end{abstract}

Keywords: Mitochondrial DNA depletion syndrome, Mitochondrial myopathy, Mitochondrial encephalomyopathy, Hepatocerebral syndrome, mtDNA, OxPhos, Alpers-Huttenlocher syndrome

\section{Introduction}

Mitochondria, present in almost all eukaryotic cells, are dynamic cellular organelles specifically involved in the production of cellular energy via the mitochondrial respiratory chain (MRC) and the oxidative phosphorylation (OxPhos) system. In addition to their most important function, ATP production, mitochondria are involved in the regulation of other cellular pathways such as calcium homeostasis, apoptosis and programmed cell death [1].

Mitochondrial disorders are a group of genetically and phenotypically pleiomorphic disorders with an estimated incidence of between 1:5,000 and 1:10,000 live births [2];

\footnotetext{
* Correspondence: laura.vilarinho@insa.min-saude.pt; filippo3364@gmail.com ${ }^{\dagger}$ Equal contributors

${ }^{1}$ National Institute of Health, Genetics Department, Research and Development Unit, Porto, Portugal

${ }^{2}$ IRCCS Stella Maris, Molecular Medicine for Neuromuscular and Neurodegenerative Diseases, Pisa, Italy

Full list of author information is available at the end of the article
}

they are often attributable to OxPhos system dysfunction, which leads to a deficiency in ATP production.

The MRC is regulated through the interaction of two physically and functionally separate genomes: the nuclear DNA (nDNA) and the mitochondrial DNA (mtDNA) genomes. Of the estimated $>1000$ proteins making up the mitochondrial proteome [3] (see also http://www.broadin stitute.org/pubs/MitoCarta/human.mitocarta.html), about 92 nDNA-encoded ones are the structural subunits forming the five multiprotein complexes embedded in the inner mitochondrial membrane. Human mtDNA encodes 13 subunits of the OxPhos complex, two ribosomal RNA (rRNA) genes and 22 transfer RNA (tRNA) genes, all of which are required for initiating protein translation and synthesis [4]. Therefore, although human mtDNA codes for the basic machinery of protein synthesis, a number of nuclear-encoded factors (including the enzymes for replication, repair and transcription) are also needed to allow protein translation. This dependency lies 
at the heart of several recently recognized human diseases that are characterized by secondary abnormalities of mtDNA. Cross-talk between the nDNA and mtDNA genomes is crucial for the maintenance of qualitative and quantitative mtDNA integrity and for correct mitochondrial protein production. Multiple deletions, depletion, or a combination of the two in critical tissues, are "hallmarks" of disease conditions arising from disrupted communication between these two genomes. Since a congruous amount of mtDNA is required to produce the key subunits of MRC complexes, mtDNA depletion will result in organ dysfunction due to insufficient synthesis of the respiratory chain components needed for adequate energy production [5].

The mtDNA depletion syndromes (MDSs) are a heterogeneous group of autosomal recessive disorders, characterized by low mtDNA levels in specific tissues. These syndromes are a consequence of defects in mtDNA maintenance caused by mutations in nuclear genes involved in either nucleotide synthesis (TK2, SUCLA2, SUCLG1, RRM2B, DGUOK, MPV17 and TYMP) or
mtDNA replication (POLG, C10orf2). The first of the above groups of genes produces proteins that maintain the mitochondrial deoxynucleotide triphosphate (dNTP) pool; dNTPs can be synthesized via either the de novo pathway (cell cycle-regulated) or the salvage pathway (in which their production involves the utilization of preexisting deoxynucleosides to synthesize DNA precursors). Given that mtDNA replicates continuously and independently of cell division, mutations in any of the genes responsible for maintaining the $\mathrm{dNTP}$ pool will result in mtDNA depletion (Figure 1). Mutations in POLG, the gene encoding the DNA polymerase gamma (POL $\gamma$ ), which is required for replication and repair of mtDNA, as well as mutations in C10orf2 (Twinkle), a mitochondrial helicase, result in impaired mitochondrial protein synthesis and an incapacity to supply sufficient mtDNA to daughter cells during cell divisions; this, in turn, leads to a reduction of mitochondrial genome content [6].

The MDSs are rare, devastating diseases that manifest typically, although not exclusively, soon after birth, and usually lead to death in infancy or early childhood.

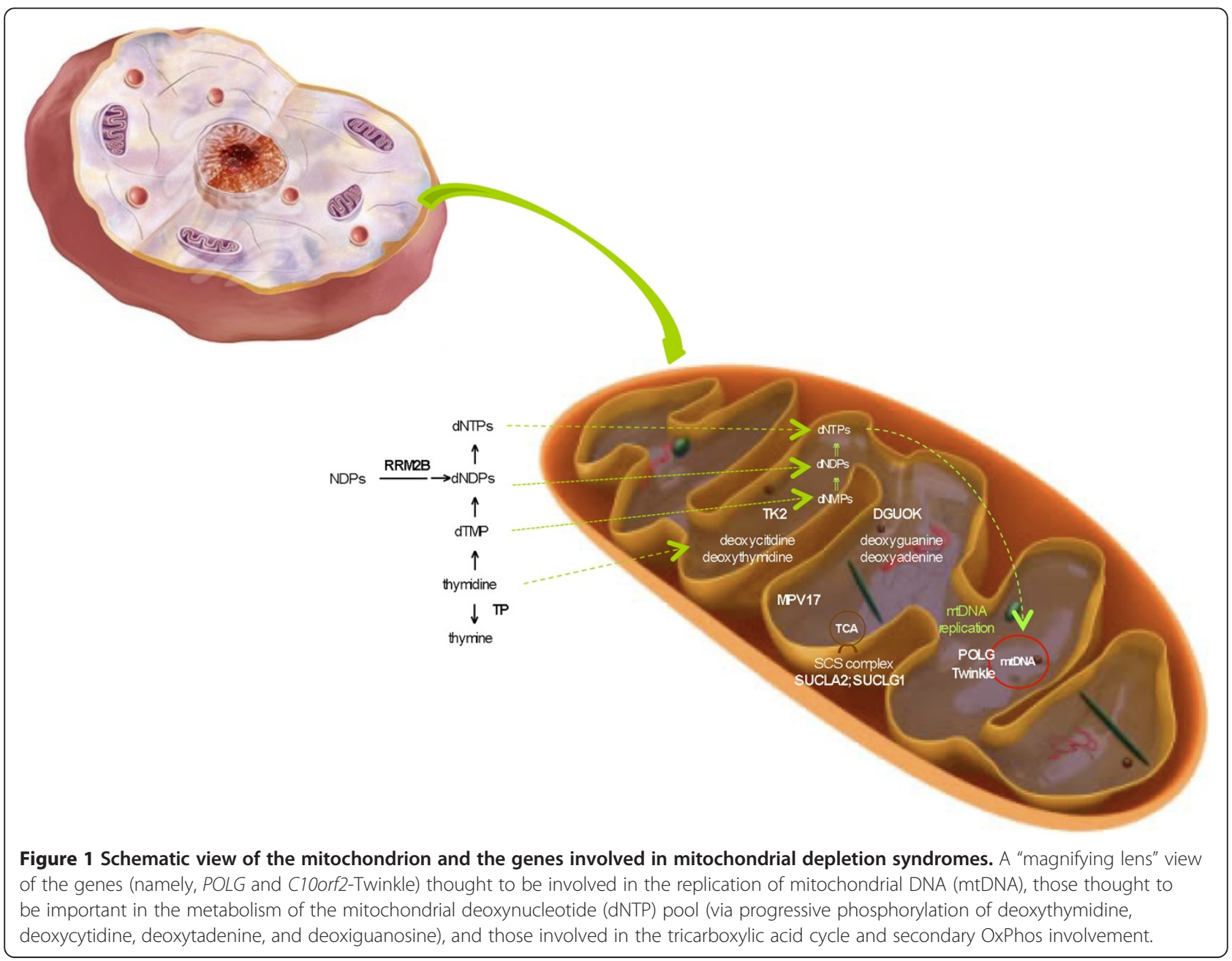


Although they often manifest themselves in a tissuespecific manner [7], it is not unknown for multiple organs, including the heart, brain, and kidneys, to be affected [8].

This paper sets out to provide an overview of the clinical manifestations and molecular etiologies of the nuclear defects involved in MDSs and to offer possible insights for improving diagnostic strategies.

The mtDNA depletion syndromes - clinical manifestations The MDSs are usually classified as myopathic, encephalomyopathic, hepatocerebral or neurogastrointestinal [9]. Table 1 summarizes the main clinical manifestations and molecular etiologies associated with these different forms.

\section{Hepatocerebral MDS}

Hepatocerebral MDS encompasses relatively common clinical conditions which, to date, have been associated with over 50 different mutations, including variants in the POLG, C10orf2, TK2, DGUOK, MPV17 and SUCLG1 genes. Their onset occurs within the first six months of life and affected subjects usually die within one year of onset. Common symptoms include persistent vomiting, failure to thrive, hypotonia and hypoglycemia associated with progressive neurological deterioration. Histological changes on liver biopsy include fatty degeneration, bile duct proliferation, fibrosis and collapse of lobular architecture. Reduced cytochome c oxidase (COX) histochemistry and combined deficiency of mtDNA-encoded MRC complexes have been detected in the livers of infants and toddlers. A peculiar form of liver failure occurs in Alpers-Huttenlocher syndrome (AHS), an earlyonset, fatal disease that is, in addition, characterized by intractable seizures that evolve into epilepsia partialis continua, and by global neurological deterioration. The liver dysfunction is usually progressive as well, evolving from microvesicular steatosis with bile duct proliferation into cirrhosis and organ failure [25,26]. Brain MRI includes signal abnormalities in the basal ganglia and thalami, irregularly widened ventricles and partial pachygyria. Patients usually present MRC deficiencies and low mtDNA in the liver, although both these markers may be normal in skeletal muscle. The prognosis is severe [27].

\section{i) DGUOK}

The deoxyguanosine kinase (DGUOK) gene lies on chromosome 2p13, and codes for a 2-deoxyribonucleoside enzyme that catalyzes the first step in the mitochondrial deoxypurine salvage pathway. More specifically, the DGUOK enzyme catalyzes the phosphorylation of purine deoxyribonucleosides into the corresponding nucleotides (deoxyguanosine and deoxyadenosine) necessary for the

Table 1 Relative frequency of mutations associated with the different mitochondrial DNA depletion syndromes (MDS, source: HGMD Professional database: www.hgmd.cf.ac.uk/)

\begin{tabular}{|c|c|c|c|c|c|c|}
\hline $\begin{array}{l}\text { Mitochondrial DNA } \\
\text { depletion syndromes }\end{array}$ & $\begin{array}{l}\text { Period } \\
\text { of onset }\end{array}$ & Clinical features & Genes (aliases) & $\begin{array}{c}\text { Chromosomal } \\
\text { LOCI }\end{array}$ & $\begin{array}{c}\text { Numbers of } \\
\text { mutations }\end{array}$ & References* \\
\hline \multirow{5}{*}{$\begin{array}{l}\text { Hepatocerebral mtDNA } \\
\text { depletion syndrome }\end{array}$} & \multirow{5}{*}{$\begin{array}{l}\text { Neonatal, early } \\
\text { childhood }\end{array}$} & \multirow{5}{*}{$\begin{array}{c}\text { Hepatic dysfunction; psychomotor } \\
\text { delay; hypotonia; lactic } \\
\text { acidosis; nystagmus; } \\
\text { neurological dysfunction }\end{array}$} & POLG (Polg1/PolgA) & $15 q 25$ & 8 & {$[10]$} \\
\hline & & & C10orf2 (Twinkle/PEO1) & $10 q 24$ & 3 & {$[11]$} \\
\hline & & & DGUOK (dGK) & $2 p 13$ & 51 & {$[12]$} \\
\hline & & & MPV17 (SYM1) & $2 p 23.3$ & 28 & {$[13]$} \\
\hline & & & TK2 & $16 q 22-q 23.1$ & 1 & {$[14]$} \\
\hline $\begin{array}{l}\text { Alpers-Huttenlocher } \\
\text { syndrome }\end{array}$ & Early childhood & $\begin{array}{l}\text { Hepatic dysfunction; epilepsia } \\
\text { partialis continua; neurological } \\
\text { dysfunction }\end{array}$ & POLG (Polg1/PolgA) & $15 q 25$ & 54 & {$[15]$} \\
\hline \multirow{4}{*}{$\begin{array}{l}\text { Myopathic mtDNA } \\
\text { depletion syndrome }\end{array}$} & \multirow{4}{*}{$\begin{array}{l}\text { Infancy, early } \\
\text { childhood }\end{array}$} & \multirow{4}{*}{$\begin{array}{l}\text { Hypotonia; muscle weakness; } \\
\text { dysarthria and dysphagia; } \\
\text { failure to thrive }\end{array}$} & POLG (Polg1/PolgA) & $15 q 25$ & 1 & {$[5]$} \\
\hline & & & TK2 & $16 q 22-q 23.1$ & 34 & {$[16]$} \\
\hline & & & $R R M 2 B(p 53 R 2)$ & $8 q 23.1$ & 3 & {$[5]$} \\
\hline & & & DGUOK (dGK) & $2 \mathrm{p} 13$ & 1 & {$[17]$} \\
\hline \multirow{4}{*}{$\begin{array}{l}\text { Encephalomyopathic } \\
\text { mtDNA depletion } \\
\text { syndrome }\end{array}$} & \multirow[t]{4}{*}{ Infancy } & \multirow{4}{*}{$\begin{array}{l}\text { Hypotonia; muscle weakness; } \\
\text { psychomotor delay; sensorineural } \\
\text { hearing impairment; lactic acidosis; } \\
\text { neurological dysfunction }\end{array}$} & $R R M 2 B(p 53 R 2)$ & $8 q 23.1$ & 14 & {$[18]$} \\
\hline & & & TK2 & $16 q 22-q 23.1$ & 1 & {$[19]$} \\
\hline & & & SUCLA2 & $13 q 12.2$ & 9 & {$[20]$} \\
\hline & & & SUCLG1 & $2 p 11.3$ & 13 & {$[21]$} \\
\hline \multirow{3}{*}{$\begin{array}{c}\text { Mitochondrial } \\
\text { neurogastrointestinal } \\
\text { encephalomyopathy }\end{array}$} & \multirow{3}{*}{$\begin{array}{l}\text { Late childhood, } \\
\text { adolescence }\end{array}$} & \multirow{3}{*}{$\begin{array}{l}\text { Gastrointestinal dysmotility; } \\
\text { weight loss; peripheral } \\
\text { neuropathy;ptosis; } \\
\text { neurological dysfunction }\end{array}$} & TYMP (ECGF1) & $22 q 13$ & 81 & {$[22]$} \\
\hline & & & $R R M 2 B(p 53 R 2)$ & $8 q 23.1$ & 2 & {$[23]$} \\
\hline & & & POLG (Polg1/PolgA) & $15 q 25$ & 1 & {$[24]$} \\
\hline
\end{tabular}

MDS are inherited in an autosomal recessive pattern; mutations in POLG gene outside MDS may be associated with autosomal recessive/dominant pattern of inheritance. * References of the first mutations published associated with the phenotype. 
maintenance of mitochondrial dNTP pools [8,28]. The typical phenotype associated with mutations in DGUOK is neonatal onset of progressive liver disease and feeding difficulties, usually associated with hypotonia, nystagmus, and psychomotor retardation by the age of three months. Most cases harbor null mutations and die before the age of two years. Peripheral neuropathy and renal tubulopathy have occasionally been reported [29]. Depletion of mtDNA has been documented mainly in the liver, where it results in combined reduction of complexes I, III and IV; the amount of mtDNA is usually normal in other tissues, at least at disease onset. Histological analyses of liver biopsies show variable findings, including microvesicular steatosis and cholestasis. Progression is usually rapid and life expectancy is low [30]. The majority of affected infants show an elevated serum concentration of tyrosine or phenylalanine on newborn screening. Intrahepatic cholestasis typically includes elevation of liver transaminases, gamma-glutamyltransferase and conjugated hyperbilirubinemia. An increased serum concentration of ferritin is often observed [31,32].

Since the initial report of pathogenic mutations in 2001 [12], more than 100 patients have been reported harboring over 50 different DGUOK mutations (fully reviewed in [9]).

\section{ii) MPV17}

The MPV17 gene is located on chromosome 2p23.3 and encodes a mitochondrial inner membrane protein whose function is not yet completely characterized, even though its key role in controlling mtDNA maintenance and OxPhos activities in mammals and yeast is well established [33]. The clinical presentation associated with mutations in MPV17 consists of severe liver failure, hypoglycemia, growth retardation, neurological symptoms and multiple brain lesions during the first year of life [34]. Marked liver depletion is found in association with biochemical deficits, with complex I or complexes I + III being most affected. Both mildly reduced mtDNA content and impaired OxPhos activities may also be noted in muscle [35]. Histological analyses of the liver have revealed swollen granular hepatocytes, and steatosis with focal pericellular and periportal fibrosis. More than 30 patients with mutations in MPV17 have been reported [9], while over 20 different mutations have been described in infantile-onset hepatocerebral syndrome and also in Navajo neurohepatopathy, an autosomal recessive multisystem disorder prevalent in the Navajo community in the Southwestern United States [28]. There exist three main subtypes: infantile (onset $<6$ months) and childhood (< 5 years) forms, characterized by hypoglycemic episodes and severe progressive liver dysfunction requiring liver transplantation, and a "classic" form characterized by moderate hepatopathy and progressive motor and sensory axonal neuropathy. The three subtypes are also associated with variable degrees of demyelination in both the central and the peripheral nervous systems.

\section{iii) POLG}

The POLG gene lies on chromosome 15q24 and encodes POL $\gamma$, the only DNA polymerase responsible for mtDNA replication and repair in mitochondria. POL $\gamma$ is composed of a catalytic subunit that has both polymerase and proofreading exonuclease activities, and an accessory subunit, which increases enzyme processivity [32]. This holoenzyme functions in conjunction with the mtDNA helicase and the mitochondrial single-stranded DNA-binding protein to form the minimal replication apparatus [36].

Over 200 mutations have been reported in the POLG gene (Human DNA Polymerase Gamma Mutation database [37]), making this gene a hot-spot for mutations associated with mitochondrial diseases $[38,39]$. Individuals affected by POLG-related disorders present with a large variety of clinical phenotypes, ranging from autosomal dominantly and recessively inherited forms of progressive external ophthalmoplegia (PEO) to juvenile spinocerebellar ataxia and epilepsy with or without dysarthria, and AHS $[27,40]$.

Approximately 45 different point mutations in POLG cause AHS [27] whose incidence has been estimated to be $\sim 1: 50,000$ [41]. The two most common POLG mutations detected in AHS, i.e., p.Ala467Thr and p.Trp748Ser, can be either homozygous or heterozygous and can be present in combination with other variants. Carrier frequency for these mutations is higher in Western countries than elsewhere. For example, in Finland it is 1:125 for p.Trp748Ser, in Norway it is 1:50, if both variants are combined, whereas $0.6 \%$ of the control Belgian population harbors p.Ala467Thr. A single ancestral founder mutation is hypothesized for both variants [6].

\section{iv) C10orf2 (Twinkle)}

The mitochondrial protein Twinkle, encoded by C10orf2/ PEO1 located on chromosome 10q24, is an mtDNA helicase, active as a homohexamer and bound to mtDNA in mitochondrial nucleoids [42]. Mutations in C10orf2 cause dominantly inherited disorders, such as pure adultonset PEO with multiple mtDNA deletions, or recessive clinical conditions including severe early-onset hepatoencephalopathy or infantile-onset spinocerebellar ataxia (IOSCA) and low mtDNA in the brain and liver, but not in skeletal muscle [6]. Neuroimaging can show cortical cerebellar atrophy; OxPhos assays show reduction of complexes I, III and IV.

Infantile-onset spinocerebellar ataxia is a severe autosomal recessive neurodegenerative disorder that manifests itself after 9-18 months of age through progressive 
atrophy of the cerebellum, brain stem and spinal cord, ataxia during the first two years of life, hypotonia with sensory axonal neuropathy, optic atrophy, hearing impairment and ophthalmoplegia [6]. Patients usually survive to adulthood. The severe neurological phenotype and the observed absence of muscle involvement in IOSCA suggest that Twinkle may play a crucial role in the maintenance and function of specific neuronal subpopulations [8].

Infantile-onset spinocerebellar ataxia is the second most common heritable ataxia in Finland, this high frequency being due to the founder effect of the p.Tyr508Cys variant and a carrier frequency of about 1:200. The same mutation has also been described in cases with severe epileptic encephalopathy and hepatic failure [43].

\section{Myopathic MDS}

The symptoms of myopathic MDS usually appear in the first year of life and consist of feeding difficulties, failure to thrive, hypotonia, muscle weakness and, occasionally, PEO. Death is often due to pulmonary insufficiency and recurrent infections, but some patients survive into their teens [44]. Muscle biopsy may show proliferation of mitochondria, and patchy or diffuse deficiency of COX. Biochemical defects are always present in all mtDNArelated respiratory chain complexes in muscle mitochondria. Serum creatine kinase levels may be variably elevated [45].

\section{i) TK2}

The TK2 gene lies on chromosome 16q22 and encodes thymidine kinase (TK2). TK2 is an intramitochondrial pyrimidine nucleoside kinase that phosphorylates dNTPs, such as deoxythymidine, deoxycytidine and deoxyuridine, thereby participating in the salvage pathway of deoxynucleotide synthesis [46]. Mitochondrial dNTP pools arise either through active transport of cytosolic dNTPs or through salvage pathways. Both pathways are essential for the replication of mtDNA, since the mitochondrion is unable to synthesize dNTPs de novo. Mutations in TK2 primarily affect muscle tissue, and have little or no effect on the liver, brain, heart or skin. The clinical presentation of TK2-related MDS is variable, with a broad phenotype. Typical manifestations include a severe, rapidly progressing myopathy of infantile or childhood onset. The disease course is rapidly progressive, leading to respiratory failure and death within months or a few years, although milder phenotypes with slower progression and longer survival have been described [6]. To date, around 50 individuals with TK2-related MDS have been reported [9]. Since the description of the first mutation in 2001 [16], 31 different pathogenic autosomal recessive mutations have been described, and the different phenotypes may be explained by variable degrees of residual activity of the mutant enzymes. Mutations in POLG and RRM2B are additional etiologies in myopathic presentations of reduced mitochondrial copy number. Milder presentations manifest as late-onset proximal muscle weakness or adult-onset progressive myopathy, with or without sensorineural hearing loss [9].

\section{Encephalomyopathic MDS}

Encephalomyopathic MDS embraces phenotypes characterized by infantile onset of hypotonia with severe psychomotor retardation, high blood lactate levels, progressive hyperkineticdystonic disorder, external ophthalmoplegia, deafness, generalized seizures and variable renal tubular dysfunction. Brain MRI is often abnormal and was initially suggested to be reminiscent of the pathological features seen in Leigh syndrome [8].

\section{i) $R R M 2 B$}

The $R R M 2 B$ gene lies on chromosome $8 \mathrm{q} 23.1$ and codes for the small subunit of p53-inducible ribonucleotide reductase, a heterotetrameric enzyme responsible for de novo conversion of ribonucleoside diphosphates into the corresponding deoxyribonucleoside diphosphates that are crucial for DNA synthesis [18]. Ribonucleotide reductase is the main regulator of the nucleotide pools in the cytoplasm and its small subunit is expressed in postmitotic cells, where it probably has a key function in maintaining the mitochondrial dNTP pools for mtDNA synthesis. Mutations in $R R M 2 B$ usually result in neonatal hypotonia, lactic acidosis, failure to thrive and tubulopathy. Psychomotor delay, sensorineural hearing loss and a profound reduction of mtDNA copy numbers in skeletal muscle [18] are also present. The disease has a rapid progression and leads to death within a few months of onset. The complex associated phenotype suggests that the consequences of defective mitochondrial dNTP pools can vary dramatically depending on the residual amount of functional enzyme. Approximately 15 affected infants have been described [9]. Of the 31 mutations described to date, 30 are associated with major phenotypes.

\section{ii) SUCLA2 and SUCLG1}

Succinyl CoA synthase is a mitochondrial matrix enzyme that catalyzes the reversible synthesis of succinate and ATP or GTP from succinyl-CoA and ADP in the tricarboxylic acid cycle. It is made up of two subunits, alpha and beta, encoded by SUCLG1 on chromosome 2p11.3 and SUCLA2 on 13q12.2-q13.3, respectively. Mutations in SUCLA2 (coding for succinate-CoA ligase, beta subunit) and SUCLG1 (coding for succinate-CoA ligase, alpha subunit) cause an encephalomyopathic form of infantile MDS, but mutations in SUCLG1 can also cause a severe disorder characterized by antenatal dysmorphisms, neonatal metabolic crisis, and early death [47]. Differences in presentation between patients might depend on 
differences in the residual amounts of the protein $[20,48,49]$. Useful diagnostic clues in succinyl CoA synthase disorders are the presence of "mildly" elevated urinary methylmalonic acid, found in all patients, and the presence of tricarboxylic acid cycle intermediates (methylcitrate, lactate, carnitine esters, 3-hydroxyisovalericacid), found in most cases. Some patients die as infants, but others survive longer. The clinical features include early childhood hypotonia, developmental delay and, almost invariably, progressive dystonia and sensorineural deafness. Mutations in SUCLA2 and SUCLG1 seem to disrupt the association between succinyl CoA synthase and mitochondrial nucleoside diphosphate kinase, resulting in mitochondrial dNTP pool imbalance and, eventually, low levels of mtDNA in muscle [21]. Twenty-three mutations were recently reported in a series of 54 individuals [9]: 10 in the 34 subjects with mutated SUCLA2 and 13 in the 20 with mutated SUCLG1.

\section{Neurogastrointestinal MDS}

Mitochondrial neurogastrointestinal encephalomyopathy (MNGIE) is an autosomal recessive disorder clinically characterized by onset between the first and fifth decades of life, although in the vast majority of cases onset occurs before the age of 20 years. All affected individuals develop weight loss and progressive gastrointestinal dysmotility manifesting as early satiety, nausea, dysphagia, gastroesophageal reflux, postprandial emesis, episodic abdominal pain with distention, and diarrhea. In addition, all affected individuals have motor and sensory demyelinating neuropathy, in some cases accompanied by axonal neuropathy. The neuropathy typically presents with distal weakness and paresthesias, showing a symmetric stocking-glove distribution. Ptosis and ophthalmoplegia are common.

Affected individuals can have elevated CSF protein and plasma lactate. Thymidine and deoxyuridine are increased in plasma. Thymidine phosphorylase (TP) enzyme activity in leukocytes is usually less than $10 \%$ of the control mean. Neuroimaging typically demonstrates diffuse white matter changes [9].

In MNGIE, mtDNA abnormalities can include depletion, multiple deletions and point mutations [50]. Mutations in TYMP and RRM2B have been linked to MNGIE, although variants in POLG have recently been detected in conditions mimicking MNGIE (so-called MNGIE-like syndromes) [24].

Skeletal muscle generally shows ragged-red fibers and defects in single or multiple OxPhos complexes, especially COX. However, MNGIE has also been reported without morphological, enzymatic, or mtDNA changes in skeletal muscle. Life expectancy is reduced (ranging from 25-60 years) [9].

\section{i) $T Y M P$}

The TYMP gene is located on chromosome 22q13 and encodes the cytosolic TP enzyme, which catalyzes the conversion of thymidine to thymine and of deoxyuridine to uracil and is therefore essential for pyrimidine catabolism. TP deficiency causes systemic accumulation of thymidine and deoxyuridine; this leads to deoxynucleotide pool imbalance and mtDNA instability, in turn resulting in the presence of multiple deletions and partial depletion of muscle mtDNA [22].

The first pathogenic mutations in the TYMP gene were described in 1999 [22] and since then over 70 mutations have been described, most associated with MNGIE.

\section{MDS - diagnostic approaches}

The suspicion of MDS is usually based on the clinical presentation, which may range from well-defined syndromes to non-specific multisystem phenotypes, and usually includes neurological involvement. Establishing a specific MDS diagnosis is challenging and requires the integration of clinical assessments, family history, biochemical testing and histopathological examination in affected tissues. It is important to obtain the appropriate biochemical and clinical information before starting any molecular investigations in order to increase the chances of a successful molecular diagnosis. Biochemical determination of MRC complexes is also important, although the results can be normal if skeletal muscle is not among the affected tissues. Quantitative real-time PCR quantification of total mtDNA content in affected tissues, using a nuclear gene as reference, is a prerequisite for correct interpretation of the amount of mtDNA present, although it is important, given the dynamic nature of mtDNA copies in different ages and tissues, to select appropriate age-matched control materials [51]. A reduction in mtDNA copy number to $60-65 \%$ of the average recorded in age-matched controls is the empirical cut-off level for a diagnosis of primary MDS. However, the reduction could be even greater, with mtDNA levels in most patients being about 20-25\% of age-matched normal controls. Biochemical data, such as lactate, pyruvate, alanine and organic acid profiles, as well as neuroimaging findings, are also important diagnostic clues. Serum CK is elevated particularly when mutations occur in TK2; serum thymidine is impaired in TYMP, and mildly elevated levels of urinary methylmalonic acid and methylcitrate occur in disorders linked to SUCLA2 or SUCLG1 [6]. Figure 2 summarizes the diagnostic algorithm in syndromes associated with mitochondrial DNA depletion. Reaching a full molecular characterization is also important for adopting appropriate therapies: the detection of changes in POLG and C10orf2 in toddlers with severe drug-resistant epilepsy should 


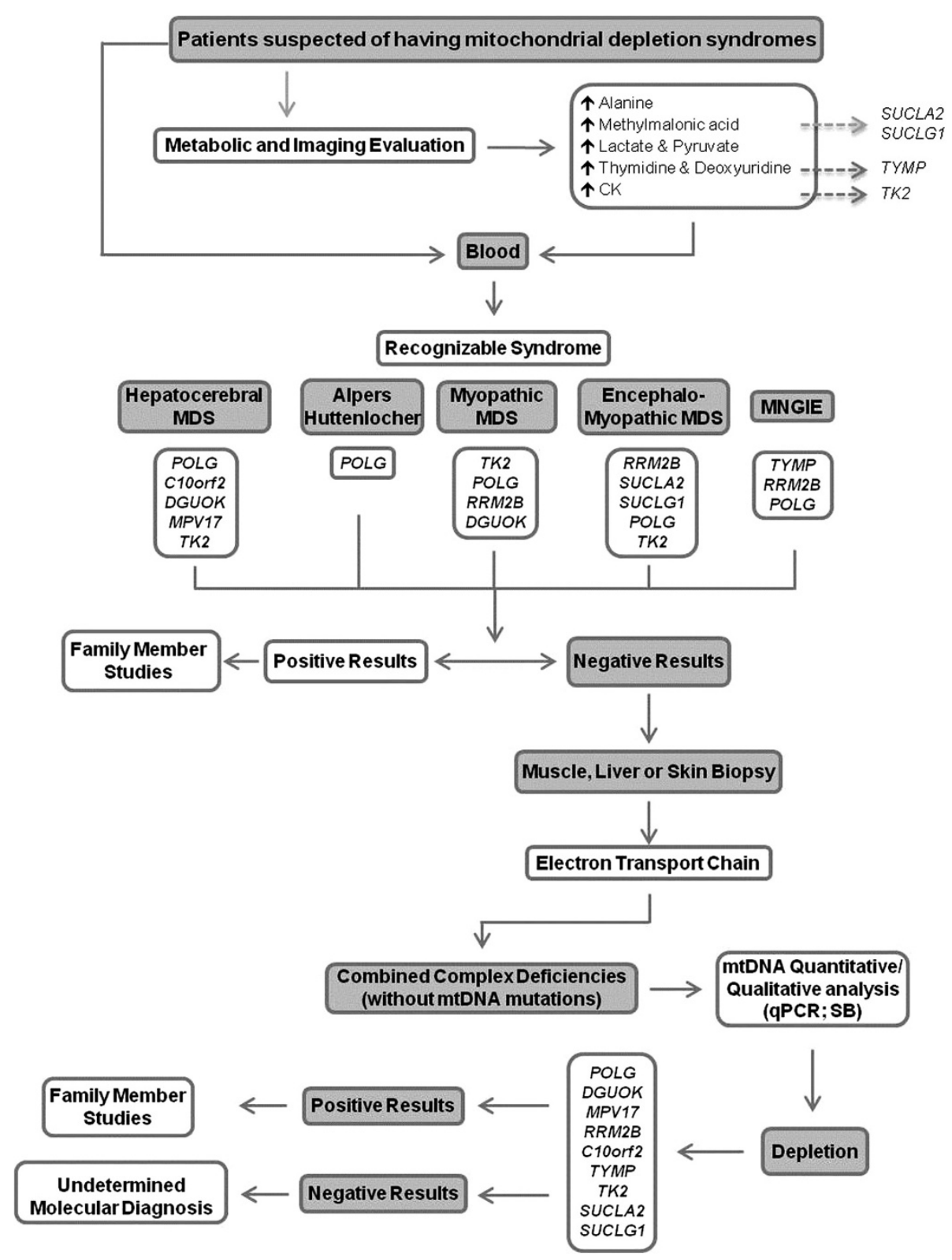

Figure 2 Diagnostic algorithm for mitochondrial depletion syndromes, based on clinical and biochemical information. Abbreviations: MDS- mitochondrial depletion syndrome; CK- creatine kinase; MNGIE- mitochondrial neurogastrolntestinal encephalomyopathy; $q P C R$ - real-time PCR; SB- Southern blot.

prompt consideration of the risk of valproate (VPA)induced liver toxicity [52].

\section{MDS - therapeutic considerations}

The management of mitochondrial diseases is largely supportive, given that there exists no "magic pill" [53]. Palliative treatments with vitamins, cofactors and respiratory substrates have been used, but they showed poor efficacy. In recent years several approaches have been adopted, mostly involving modulation of the different pathways regulating mitochondrial biogenesis [39], but they have yet to be applied in the clinic. Meanwhile, some therapeutic avenues have been tried in clinical practice, although none has shown evidence-based efficacy.

Liver transplantation may be beneficial to patients with hepatopathy caused by $D G U O K$ mutations if no neurological symptoms have developed. However, it would be contraindicated in the presence of significant hypotonia, psychomotor retardation or nystagmus [31]. In patients with MPV17, and in VPA-induced organ failure, transplantation has increased quality of life and life expectancy in some patients [5,54], but liver-transplanted children 
may go on to develop neurological symptoms [55,56]. A controlled diet, avoiding hypoglycemia, has been proposed to slow down disease progression and allow supportive care [57]. Some improvement was suggested with succinate or coenzyme Q10 together with a lipid-rich diet [58]. Furthermore, folate levels may be deficient in the CSF of some patients and detection of low folate in the CSF may prompt replacement therapy [59]. Levocarnitine, creatine monohydrate, coenzyme Q10, B vitamins, and antioxidants, such as alpha lipoic acid, vitamin $\mathrm{E}$, and vitamin $\mathrm{C}$, have often been used as pro-energy supplements in mitochondrial disorders in general and in MDS in particular, but longer follow-ups are necessary to evaluate the opportuneness of recommending such dietary interventions [53]. In MNGIE, a correlation between plasma thymidine levels and the severity of the phenotype has been observed [60]. Therefore, attempts to reduce the circulating nucleotide levels could result in disease improvement. Enzyme replacement therapy has been used in MNGIE: infusions of platelets from healthy donors reduced circulating thymidine and deoxyuracile levels and partially restored TP activity. The limitation of this therapy was the short half-life of the platelets [61]. Allogeneic stem cell transfusions have been given to two patients with MNGIE [62,63]; although more experience is needed to illustrate the clinical benefit of this treatment, it opens up a therapeutic possibility for disorders of nucleoside metabolism. Finally, continuous ambulatory peritoneal dialysis has also been used in MNGIE to reduce thymidine levels, and this treatment improved symptoms during a three-year follow-up [64].

\section{Concluding remarks}

A mitochondrial disease manifesting at, or soon after, birth is more likely to be associated with nDNA than with mtDNA mutations [39], but until very recently our ignorance regarding the mechanisms underlying mitochondrial gene transcription and translation and the complex interaction between the "two genomes" limited our diagnostic power.

Mitochondrial DNA depletion, which can result from any imbalance in the mitochondrial nucleotide pool available for mtDNA replication, as well as abnormalities in mitochondrial replication machinery, has become an increasingly important cause of a wide spectrum of infantile and childhood-onset tissue-specific and multisystem disorders [65]. Consistent with the different phenotypes, mtDNA depletion may affect a specific tissue type (most commonly brain and muscle or liver tissue) or multiple organs, including the heart and kidneys. More than 75\% of MDS patients develop full-blown disease within the first year of life, and it is rapidly fatal in most cases $[11,66]$. Identifying the causative genes is important not only to allow adequate antenatal options, family planning and prenatal diagnosis, but also to improve understanding of the disease pathophysiology and, therefore, improve therapeutic options. From this perspective, the recent advances in the clinical use of next generation sequencing (NGS) technologies will likely facilitate molecular diagnosis of these conditions in the coming years [67-69]. Since NGS is becoming a feasible option in several Mendelian disorders and inborn errors of metabolism [70], it promises to allow the identification of a greater number of patients with mitochondrial disorders as well $[71,72]$. This would likely resolve some of the open issues emerging from clinical practice in this field, which include difficulties in diagnosing the conditions and in providing adequate counseling, and unpredictable prognoses. An accurate and focused diagnostic workup would also save health-related resources and family distress. Only by achieving a full understanding of the molecular basis of MDS will we be able to gather insights for novel and effective therapeutic strategies.

\section{Competing interests}

The authors declare no conflicts of interest for the present paper.

\section{Authors' contributions}

All the authors have made substantial contributions to conception and design of the review. All the authors have been involved in drafting the manuscript and revising it critically. All the authors read and approved the final manuscript.

\section{Acknowledgments}

CN was supported by the Portuguese Foundation for Science and Technology (SFRH/BD/45247/2008). LSA was supported by the Portuguese Foundation for Science and Technology (FCT C2008/INSA/P4). We thank Catherine J. Wrenn for her expert language editing.

\section{Author details}

${ }^{1}$ National Institute of Health, Genetics Department, Research and Development Unit, Porto, Portugal. ${ }^{2}$ RCCS Stella Maris, Molecular Medicine for Neuromuscular and Neurodegenerative Diseases, Pisa, Italy. ${ }^{3}$ ICBASInstituto de Ciências Biomédicas de Abel Salazar, University of Porto, Porto, Portugal. ${ }^{4}$ Department of Child Neurology and Neurogenetics, IRCCS Stella Maris, University of Pisa, via dei Giacinti 2, Calambrone, Pisa 56128, Italy.

${ }^{5}$ Newborn Screening Metabolism and Genetics Unit, Department of Genetics, National Institute of Health, Rua Alexandre Herculano, 321, Porto 4000-055, Portugal.

Received: 19 November 2013 Accepted: 28 March 2014 Published: 3 April 2014

\section{References}

1. van der Giezen M, Tovar J: Degenerate mitochondria. EMBO Rep 2005, 6(Suppl 6):525-530.

2. Schaefer AM, Taylor RW, Turnbull DM, Chinnery PF: The epidemiology of mitochondrial disorders- past, present and future. Biochim Biophys Acta 2004, 1659(Suppl 2-3):115-120.

3. Pagliarini DJ, Calvo SE, Chang B, Sheth SA, Vafai SB, Ong SE, Walford GA, Sugiana C, Boneh A, Chen WK, Hill DE, Vidal M, Evans JG, Thorburn DR, Carr SA, Mootha VK: A mitochondrial protein compendium elucidates complex I disease biology. Cell 2008, 134:112-123.

4. DiMauro S: Mitochondrial medicine. Biochim Biophys Acta 2004 1659:107-114

5. Spinazzola A, Invernizzi F, Carrara F, Lamantea E, Donati A, Dirocco M, Giordano I, Meznaric-Petrusa M, Baruffini E, Ferrero I, Zeviani M: Clinical and molecular features of mitochondrial DNA depletion syndromes. J Inherit Metab Dis 2009, 32:143-158. 
6. Lee $Y-S$, Kennedy WD, Yin YW: Structural insight into processive human mitochondrial DNA synthesis and disease-related polymerase mutations. Cell 2009, 139:312-324

7. Nogueira C, Carrozzo R, Vilarinho L, Santorelli FM: Infantile-onset disorders of mitochondrial replication and protein synthesis. J Child Neurol 2011 26(Suppl 7):866-875

8. Spinazzola A, Zeviani M: Disorders of nuclear-mitochondrial intergenomic communication. Biosci Rep 2007, 27(Suppl 1-3):39-51.

9. El-Hattab AW, Scaglia F: Mitochondrial DNA depletion syndromes: review and updates of genetic basis, manifestations, and therapeutic options. Neurotherapeutics 2013, 10(Suppl 2):186-198.

10. Ferrari G, Lamantea E, Donati A, Filosto M, Briem E, Carrara F, Parini R, Simonati A, Santer R, Zeviani M: Infantile hepatocerebral syndromes associated with mutations in the mitochondrial DNA polymerase-gammaA. Brain 2005, 128(4):723-731.

11. Sarzi E, Bourdon A, Chrétien D, Zarhrate M, Corcos J, Slama A, Cormier-Daire $V$, de Lonlay P, Munnich A, Rötig A: Mitochondrial DNA depletion is a prevalent cause of multiple respiratory chain deficiency in childhood. J Pediatr 2007, 150:531-534.

12. Mandel H, Szargel R, Labay $V$, Elpeleg $O$, Saada A, Shalata A, Anbinder $Y$, Berkowitz D, Hartman C, Barak M, Eriksson S, Cohen N: The deoxyguanosine kinase gene is mutated in individuals with depleted hepatocerebral mitochondrial DNA. Nat Genet 2001, 29(Suppl 3):337-341.

13. Spinazzola A, Viscomi C, Fernandez-Vizarra E, Carrara F, D'Adamo P, Calvo S, Marsano RM, Donnini C, Weiher H, Strisciuglio P, Parini R, Sarzi E, Chan A, DiMauro S, Rötig A, Gasparini P, Ferrero I, Mootha VK, Tiranti V, Zeviani M: MPV17 encodes an inner mitochondrial membrane protein and is mutated in infantile hepatic mitochondrial DNA depletion. Nat Genet 2006, 38(5):570-575.

14. Zhang S, Li FY, Bass HN, Pursley A, Schmitt ES, Brown BL, Brundage EK, Mardach R, Wong LJ: Application of oligonucleotide array CGH to the simultaneous detection of a deletion in the nuclear TK2 gene and mtDNA depletion. Mol Genet Metab 2010, 99(1):53-57.

15. Naviaux RK, Nguyen KV: POLG mutations associated with Alpers' syndrome and mitochondrial DNA depletion. Ann Neurol 2004, 55(5):706-712

16. Saada A, Shaag A, Mandel H, Nevo Y, Eriksson S, Elpeleg O: Mutant mitochondrial thymidine kinase in mitochondrial DNA depletion myopathy. Nat Genet 2001, 29(Suppl 3):342-344.

17. Buchaklian AH, Helbling D, Ware SM, Dimmock DP: Recessive deoxyguanosine kinase deficiency causes juvenile onset mitochondrial myopathy. Mol Genet Metab 2012, 107(1-2):92-94.

18. Bourdon A, Minai L, Serre V, Jais JP, Sarzi E, Aubert S, Chrétien D, de Lonlay $P$, Paquis-Flucklinger $V$, Arakawa $H$, Nakamura $Y$, Munnich A, Rötig A Mutation of RRM2B, encoding p53- controlled ribonucleotide reductase (p53R2), causes severe mitochondrial DNA depletion. Nat Genet 2007, 39:776-780.

19. Lesko N, Naess K, Wibom R, Solaroli N, Nennesmo I, von Döbeln U, Karlsson A, Larsson NG: Two novel mutations in thymidine kinase-2 cause early onset fatal encephalomyopathy and severe mtDNA depletion. Neuromuscul Disord 2010, 20(3):198-203.

20. Elpeleg O, Miller C, Hershkovitz E, Bitner-Glindzicz M, Bondi-Rubinstein G, Rahman S, Pagnamenta A, Eshhar S, Saada A: Deficiency of the ADP-forming succinyl-CoA synthase activity is associated with encephalomyopathy and mitochondrial DNA depletion. Am J Hum Genet 2005, 76(Suppl 6):1081-1086

21. Ostergaard E, Christensen E, Kristensen E, Mogensen B, Duno M, Shoubridge EA, Wibrand F: Deficiency of the alpha subunit of succinate-coenzyme A ligase causes fatal infantile lactic acidosis with mitochondrial DNA depletion. Am J Hum Genet 2007, 81(Suppl 2):383-387.

22. Nishino I, Spinazzola A, Hirano M: Thymidine phosphorylase gene mutations in MNGIE, a human mitochondrial disorder. Science 1999, 283:689-692.

23. Shaibani A, Shchelochkov OA, Zhang S, Katsonis P, Lichtarge O, Wong $L_{\text {, }}$ Shinawi M: Mitochondrial neurogastrointestinal encephalopathy due to mutations in RRM2B. Arch Neurol 2009, 66(8):1028-1032.

24. Tang S, Dimberg EL, Milone M, Wong L-J: Mitochondrial neurogastrointestinal encephalomyopathy (MNGIE)-like phenotype: an expanded clinical spectrum of POLG1 mutations. J Neurol 2012, 259:862-868.

25. Cohen BH, Naviaux RK: The clinical diagnosis of POLG disease and other mitochondrial DNA depletion disorders. Methods 2010, 51:364-373.
26. Naviaux RK, Nyhan WL, Barshop BA, Poulton J, Markusic D, Karpinski NC, Haas RH: Mitochondrial DNA polymerase gamma deficiency and mtDNA depletion in a child with Alpers' syndrome. Ann Neurol 1999, 45:54-58.

27. Rötig A, Poulton J: Genetic causes of mitochondrial DNA depletion in humans. Biochim Biophys Acta 2009, 1792(Suppl 12):1103-1108.

28. Copeland WC: Defects in mitochondrial DNA replication and human disease. Crit Rev Biochem Mol Biol 2012, 47(1):64-74.

29. Rahman S, Poulton J: Diagnosis of mitochondrial DNA depletion syndromes. Arch Dis Child 2009, 94(Suppl 1):3-5.

30. Ji JQ, Dimmock D, Tang LY, Descartes M, Gomez R, Rutledge SL, Schmitt ES, Wong L: A novel c.592-4_c.592-3delTT mutation in DGUOK gene causes exon skipping. Mitochondrion 2010, 10:188-191.

31. Dimmock DP, Zhang Q, Dionisi-Vici C, Carrozzo R, Shieh J, Tang LY, Truong C, Schmitt E, Sifry-Platt M, Lucioli S, Santorelli FM, Ficicioglu CH, Rodriguez M, Wierenga K, Enns GM, Longo N, Lipson MH, Vallance $H$, Craigen WJ, Scaglia F, Wong LJ: Clinical and molecular features of mitochondrial DNA depletion due to mutations in deoxyguanosine kinase. Hum Mutat 2008, 29(Suppl 2):330-331

32. Kaguni LS: DNA polymerase gamma, the mitochondrial replicase. Annu Rev Biochem 2004, 73:293-320.

33. Dallabona C, Marsano RM, Arzuffi P, Ghezzi D, Mancini P, Zeviani M, Ferrero I, Donnini C: Sym1, the yeast ortholog of the MPV17 human disease protein, is a stress-induced bioenergetic and morphogenetic mitochondrial modulator. Hum Mol Genet 2010, 15(19(Suppl 6)):1098-1107.

34. Wong $\sqcup$, Brunetti-Pierri N, Zhang Q, Yazigi N, Bove KE, Dahms BB, Puchowicz MA, Gonzalez-Gomez I, Schmitt ES, Truong CK, Hoppel CL, Chou PC, Wang J, Baldwin EE, Adams D, Leslie N, Boles RG, Kerr D, Craigen WJ: Mutations in the MPV17 gene are responsible for rapidly progressive liver failure in infancy. Hepatology 2007, 46:1218-1227.

35. Alberio $S$, Mineri $R$, Tiranti $V$, Zeviani M: Depletion of mtDNA: syndromes and genes. Mitochondrion 2007, 7:6-12.

36. Korhonen JA, Pham XH, Pellegrini M, Falkenberg M: Reconstitution of a minimal mtDNA replisome in vitro. EMBO J 2004, 23:2423-2429.

37. Human DNA Polymerase Gamma Mutation Database. http://tools.niehs. nih.gov/polg/. 2009.

38. Chinnery PF, Zeviani M: $155^{\text {th }}$ ENMC workshop: polymerase gamma and disorders of mitochondrial DNA synthesis. Neuromuscul Disord 2008, 18:259-267.

39. Dimauro S, Schon EA, Carelli V, Hirano M: The clinical maze of mitochondrial neurology. Nat Rev Neurol 2013, 9(Suppl 8):429-444.

40. DiMauro S, Garone C: Historical perspective on mitochondrial medicine. Dev Disabil Res Rev 2010, 16:106-113.

41. Darin N, Oldfors A, Moslemi AR, Holme E, Tulinius M: The incidence of mitochondrial encephalomyopathies in childhood: clinical features and morphological, biochemical, and DNA anbormalities. Ann Neurol 2001 49(3):377-383

42. Spelbrink JN, Li FY, Tiranti V, Nikali K, Yuan QP, Tariq M, Wanrooij S, Garrido N, Comi G, Morandi L, Santoro L, Toscano A, Fabrizi GM, Somer H, Croxen R, Beeson D, Poulton J, Suomalainen A, Jacobs HT, Zeviani M, Larsson C: Human mitochondrial DNA deletions associated with mutations in the gene encoding Twinkle, a phage T7 gene 4-like protein localized in mitochondria. Nat Genet 2001, 28(Suppl 3):223-231.

43. Hakonen $A H$, Isohanni $P$, Paetau A, Herva $R$, Suomalainen $A$, Lonnqvist $T$ : Recessive Twinkle mutations in early onset encephalopathy with mtDNA depletion. Brain 2007, 130(Suppl 11):3032-3040.

44. Moraes CT, Shanske S, Tritschler HJ, Aprille JR, Andreetta F, Bonilla E, Schon EA, DiMauro S: MtDNA depletion with variable tissue expression: a nove genetic abnormality in mitochondrial diseases. Am J Hum Genet 1991, 48:492-501.

45. Spinazzola A, Zeviani M: Disorders of nuclear-mitochondrial intergenomic signaling. Gene 2005, 354(Suppl 18):162-168

46. Oskoui M, Davidzon G, Pascual J, Erazo R, Gurgel-Giannetti J, Krishna S, Bonilla E, De Vivo DC, Shanske S, DiMauro S: Clinical spectrum of mitochondrial DNA depletion due to mutations in the thymidine kinase 2 gene. Arch Neurol 2006, 63:1122-1126.

47. Rivera H, Merinero B, Martinez-Pardo M, Arroyo I, Ruiz-Sala P, Bornstein B, Serra-Suhe C, Gallardo E, Marti R, Moran MJ, Ugalde C, Perez-Jurado LA, Andreu AL, Garesse R, Ugarte M, Arenas J, Martin MA: Marked mitochondrial DNA depletion associated with a novel SUCLG1 gene mutation resulting in lethal neonatal acidosis, multi-organ failure, and interrupted aortic arch. Mitochondrion 2010, 10(4):362-368. 
48. Morava E, Steuerwald U, Carrozzo R, Kluijtmans LA, Joensen F, Santer R, Dionisi-Vici C, Wevers RA: Dystonia and deafness due to SUCLA2 defect; Clinical course and biochemical markers in 16 children. Mitochondrion 2009, 9:438-442.

49. Rouzier C, Le Guédard-Méreuze S, Fragaki K, Serre V, Miro J, Tuffery-Giraud S, Chaussenot A, Bannwarth S, Caruba C, Ostergaard E, Pellissier JF, Richelme C, Espil C, Chabrol B, Paquis-Flucklinger V: The severity of phenotype linked to SUCLG1 mutations could be correlated with residual amount of SUCLG1 protein. J Med Genet 2010, 47:670-676.

50. Hirano M, Silvestri G, Blake DM, Lombes A, Minetti C, Bonilla E, Hays AP, Lovelace RE, Butler I, Bertorini TE, Threlkeld AB, Mitsumoto H, Salberg LM, Rowland LP, DiMauro S: Mitochondrial neurogastrointestinal encephalomyopathy (MNGIE): clinical, biochemical, and genetic features of an autosomal recessive mitochondrial disorder. Neurology 1994, 44:721-727.

51. Morten K, Ashley N, Wijburg F, Hadzic N, Parr J, Jayawant S, Adams S, Bindoff L, Bakker HD, Mieli-Vergani G, Zeviani M, Poulton J: Liver mtDNA content increases during development: a comparison of methods and the importance of age- and tissue specific controls for the diagnosis of mtDNA depletion. Mitochondrion 2007, 7:386-395.

52. Stewart JD, Horvath $R$, Baruffini E, Ferrero I, Bulst $S$, Watkins PB, Fontana RJ, Day CP, Chinnery PF: Polymerase y gene POLG determines the risk of sodium valproate-induced liver toxicity. Hepatology 2010, 52(Suppl):1791-1796.

53. Pfeffer G, Horvath R, Klopstock T, Mootha VK, Suomalainen A, Koene S, Hirano M, Zeviani M, Bindoff LA, Yu-Wai-Man P, Hanna M, Carelli V, McFarland R, Majamaa K, Turnbull DM, Smeitink J, Chinnery PF: New treatments for mitochondrial disease-no time to drop our standards. Nat Rev Neurol 2013, 9(Suppl 8):474-481.

54. El-Hattab AW, Li FY, Schmitt E, Zhang S, Craigen WJ, Wong LJ: MPV17associated hepatocerebral mitochondrial DNA depletion syndrome: new patients and novel mutations. Mol Genet Metab 2009, 1792(Suppl 12):1109-1112.

55. Delarue A, Paut O, Guys JM, Montfort MF, Lethel V, Roquelaure B, Pellissier JF, Sarles J, Camboulives J: Inappropriate liver transplantation in a child with Alpers-Huttenlocher syndrome misdiagnosed as valproate-induced acute liver failure. Pediatr Transplant 2000, 4:67-71.

56. Kayihan N, Nennesmo I, Ericzon BG, Nemeth A: Fatal deterioration of neurological disease after orthotopic liver transplantation for valproic acidinduced liver damage. Pediatr Transplant 2000, 4:211-214.

57. Parini $R$, Furlan F, Notarangelo L, Spinazzola A, Uziel G, Strisciuglio $P$, Concolino D, Corbetta C, Nebbia G, Menni F, Rossi G, Maggioni M, Zeviani M: Glucose metabolism and diet-based prevention of liver dysfunction in MPV17 mutant patients. J Hepatol 2009, 50:215-221.

58. Kaji S, Murayama K, Nagata I, Nagasaka H, Takayanagi M, Ohtake A, Iwasa H, Nishiyama M, Okazaki Y, Harashima H, Eitoku T, Yamamoto M, Matsushita H, Kitamoto K, Sakata S, Katayama T, Sugimoto S, Fujimoto Y, Murakami t, Kanzaki S, Shiraki K: Fluctuating liver functions in siblings with MPV17 mutations and possible improvement associated with dietary and pharmaceutical treatments targeting respiratory chain complex II. Mol Genet Metab 2009, 97:292-296.

59. Hasselmann O, Blau N, Ramaekers VT, Quadros EV, Sequeira JM, Weissert M: Cerebral folate deficiency and CNS inflammatory markers in Alpers disease. Mol Genet Metab 2010, 99(Suppl 1):58-61.

60. Lara MC, Weiss B, Illa I, Madoz P, Massuet L, Andreu AL, Valentino ML, Anikster $Y$, Hirano M, Martí R: Infusion of platelets transiently reduces nucleoside overload in MNGIE. Neurology 2006, 67:1461-1463.

61. Lara MC, Valentino ML, Torres-Torronteras J, Hirano M, Marti R Mitochondrial neurogastrointestinal encephalomyopathy (MNGIE): biochemical features and therapeutic approaches. Biosci Rep 2007, 27:151-163.

62. Hirano M, Marti R, Casali C, Tadesse S, Uldrick T, Fine B, Escolar DM, Valentino ML, Nishino I, Hesdorffer C, Schwartz J, Hawks RG, Martone DL, Cairo MS, DiMauro S, Stanzani M, Garvin JH Jr, Savage DG: Allogeneic stem cell transplantation corrects biochemical derangements in MNGIE. Neurology 2006, 67:1458-1460.

63. Filosto M, Scarpelli M, Tonin P, Lucchini G, Pavan F, Santus F, Parini R, Donati MA, Cotelli MS, Vielmi V, Todeschini A, Canonico F, Tomelleri G, Padovani A, Rovelli A: Course and management of allogeneic stem cell transplantation in patients with mitochondrial neurogastrointestinal encephalomyopathy. J Neurol 2012, 259(Suppl 12):2699-2706.
64. Yavuz H, Ozel A, Christensen M, Christensen E, Schwartz M, Elmaci M, Vissing J: Treatment of mitochondrial neurogastrointestinal encephalomyopathy with dialysis. Arch Neurol 2007, 64:435-438.

65. Finsterer J, Ahting U: Mitochondrial depletion syndromes in children and adults. Can J Neurol Sci 2013, 40:635-644.

66. Hirano M, Marti R, Ferreiro-Barros C, Vilà MR, Tadesse S, Nishigaki Y, Nishino I, Vu TH: Defects of intergenomic communication: autosomal disorders that cause multiple deletions and depletion of mitochondrial DNA. Semin Cell Dev Biol 2001, 12(Suppl 6):417-427.

67. Vasta V, Ng SB, Turner EH, Shendure J, Hahn SH: Next generation sequence analysis for mitochondrial disorders. Genome Med 2009, 1(Suppl 10):100.

68. Calvo SE, Compton AG, Hershman SG, Lim SC, Lieber DS, Tucker EJ, Laskowski A, Garone C, Liu S, Jaffe DB, Christodoulou J, Fletcher JM, Bruno DL, Goldblatt J, Dimauro S, Thorburn DR, Mootha VK: Molecular diagnosis of infantile mitochondrial disease with targeted next-generation sequencing. Sci Trans/ Med 2012, 4(Suppl 118):118ra10.

69. Haack TB, Haberberger B, Frisch EM, Wieland T, Luso A, Gorza M, Strecker V Graf E, Mayr JA, Herberg U, Hennermann JB, Klopstock T, Kuhn KA, Ahting U, Sperl W, Wilichowski E, Hoffmann GF, Tesarova M, Hansikova H, Zeman J, Plecko B, Zeviani M, Wittig I, Strom TM, Schuelke M, Freisinger P, Meitinger T, Prokisch H: Molecular diagnosis in mitochondrial complex I deficiency using exome sequencing. J Med Genet 2012, 49(Suppl 4):277-283.

70. Shendure J, Lieberman Aiden E: The expanding scope of DNA sequencing. Nat Biotechnol 2012, 30:1084-1094.

71. Dündar H, Ozgül RK, Yalnızoglu D, Erdem S, Oguz KK, Tuncel D, Temuçin CM, Dursun A: Identification of a novel Twinkle mutation in a family with infantile onset spinocerebellar ataxia by whole exome sequencing. Pediatr Neurol 2012, 46:172-177.

72. Lieber DS, Calvo SE, Shanahan K, Slate NG, Liu S, Hershman SG, Gold NB, Chapman BA, Thorburn DR, Berry GT, Schmahmann JD, Borowsky ML, Mueller DM, Sims KB, Mootha VK: Targeted exome sequencing of suspected mitochondrial disorders. Neurology 2013, 80:1762-1770.

doi:10.1186/1824-7288-40-34

Cite this article as: Nogueira et al: Syndromes associated with mitochondrial DNA depletion. Italian Journal of Pediatrics 2014 40:34

\section{Submit your next manuscript to BioMed Central and take full advantage of:}

- Convenient online submission

- Thorough peer review

- No space constraints or color figure charges

- Immediate publication on acceptance

- Inclusion in PubMed, CAS, Scopus and Google Scholar

- Research which is freely available for redistribution 